\title{
Smartphone Addiction among Sultan Qaboos University Undergraduates
}

Hafidha suleiman Al-Barashdi, Sultan Qaboos University, p012307@squ.edu.om Prof. Dr. Abdelmajid Bouazza, Sultan Qaboos University, bouazza93@gmail.com ABSTRACT

Dr. Naeema H. Jabr, Sultan Qaboos University, mnjaburh@hotmail.com

In addition to the study's main focus on smartphone addiction among SQU undergraduates, it also investigated particular issues such as the following: smartphone applications and activities that students were most addicted to, the impact of addiction on academic achievement, and addiction variation according to gender, field of study, parental education and family income. A questionnaire was distributed to a random sample of 140 undergraduates $(37.1 \%$ males and $62.9 \%$ females). Findings revealed that what the study calls a casual level of addiction (42.3\%) was the most common, followed by a heavy level $(30.8 \%)$, and finally a moderate level (26.\%). While messaging was the activity students were most addicted to, no significant differences were found that related to academic achievement. Males were more addicted than females, but nothing significant emerged in relation to field of study, parental education and family income.

\section{Indexing terms/Keywords}

Smartphone addiction, undergraduate students, Sultan Qaboos University, Oman

\section{Academic Discipline And Sub-Disciplines}

Psychology, Behavioral Medicine, Behavioral Addiction

\section{SUBJECT CLASSIFICATION}

RC569.5.154

\section{TYPE (METHOD/APPROACH)}

Quantitative Method

\section{Council for Innovative Research}

Peer Review Research Publishing System

\section{Journal: Journal of Social Sciences Research}

Vol. 5, No. 2 


\section{Introduction}

The Smartphone has been changing the ways in which people communicate with others, find information, have fun and manage their everyday lives. Furthermore, the recent development of new operating systems, abundant applications and competition between vendors has facilitated a remarkable growth in the number of users (Park, Kim, Shon and Shim, 2013). As a result, Smartphone use is rapidly spreading world-wide. In fact, the global mobile phone market now stands at approximately 6.8 billion subscribers (International Telecommunication Union, 2013), more than 1.08 billion of them being Smartphone users. Oman is no exception. According to the Telecommunication Regulatory Authority (TRA), mobile phone penetration rate (the number of subscriptions per 100 people) was $190.29 \%$ at the end of Q4 2012 (TRA, 2012). Today, the widespread use of Smartphones can be attributed to many factors among which are fast, lightness, strength. Also, these phones come with different features that attract users, such as a digital camera, a movie camera, a diary, a phone book, a GPS, a radio, an MP3 player, a web browser, a data storage device, an encyclopedia, an alarm clock, a dictaphone, a personal organizer, a flashlight and a lot more. All this makes the majority of people in both developed and developing countries use mobile phones (Takao, Takahashi and kitamura, 2009).

While Smartphone use has been increasing across economic and age sectors, university students have been seen as one of the most important target markets and the largest consumer group of Smartphone services (Head and Ziolkowski, 2012). Likewise, Bianchi and Phillips (2005) reveal that the highest level of problematic mobile phone use was most found among younger users, from which it can be argued that mobile phone addiction is most likely to occur among this group. Hong, Chiu and Huang (2012) argue that mobile phones are popular among university students because they increase their social communication and expand their opportunities for making social relationships. However, although this expanding use of Smartphones among university students has provided them with an easy way of communication, Smartphones can also lead to many problems (Hassanzadeh and Rezaei, 2011). Their overuse reduces students' concentration during class and hence affects their academic achievement and causes addiction.

For Krajewska-Kułak et al. (2012) "problematic mobile phone use can be considered to be an addiction-like behavior" ( $p$. 46). Similarly, Griffiths (1996) considered technological addiction as a subset of behavioral addiction. He defined it as a behavioral addiction that involves human-machine interaction and is non-chemical in nature.

Although no previous study investigated Smartphone addiction in Oman, some studies on Internet addiction among university students revealed that they were heavy users. In this regard, Jabr (2011) found that (31\%) of SQU students confirmed that they were addicted to using the Internet. She also found that they were addicted to using the Internet in areas related to Smartphones too. These were as follows: checking and sending e-mails, using the university website, following online courses through Moodle and WebCT, connecting to SN sites, downloading audios and videos, accessing online applications of the spreadsheet, documents, presentations and forms, using the SQU Main Library website, downloading pictures and contributing to wikis. Likewise, Bouazza (2001), examining the reality of Internet use by SQU students, found that students at the College of Science were the heaviest users of the Internet. Hence, the aim of this study is to provide a comprehensive understanding of Smartphone addiction and its impact on SQU undergraduates' academic achievement. To this end, the study will focuses on the following:

1) Investigating the percentages of Smartphone addiction levels among SQU undergraduate students.

2) Identifying the symptoms of Smartphone addiction among SQU undergraduate students.

3) Exploring the most addictive Smartphone's activities and applications among SQU undergraduates.

4) Clarifying the impact of Smartphone addiction among SQU undergraduates on their academic achievement.

5) Highlighting the significant differences in Smartphone addiction among SQU undergraduates according to their gender, field of study, parents educational level and family income level.

\section{Problem Statement}

The technological revolution has provided the world with many of inventions. However, every invention has brought with it comforts as well as threatening effects. It is the same with Smartphones (Ahmed, Qazi and Perji, 2011).

Smartphone use has become vital to university students because they use them for several purposes not only similar to what the Internet provides, but also for many applications which provide new functions. These functions allow students not to communicate with others face-to-face or instantly which is a perfect way for shy students to communicate with others. In addition, other Smartphones functions allow students to enjoy kinds of entertainment like games. They can also get information while surfing on the Internet which helps them to escape from uncomfortable situations. As a result, it seems that many students tend to rely heavily on their phones, which will lead to heavier use (Casey, 2012).

However, Mathews, Pierce and Tang (2009) have provided some initial evidence to support the view that Smartphone users face a greater risk of developing addiction. Indeed, Smartphone use has already been described as a compulsive and addictive disorder which looks set to become one of the biggest non-drug addictions in the 21st century (Madrid, 2003). Similarly, Glaser (2007) has indicated that "for young people especially, having a mobile phone or iPod in hand and at the ready is the default mode while walking in the streets" (p. 1). It is a trend that can be easily observed when students are in their own world occupied by their Smartphones. 
The risk of Smartphone addiction represents a growing psychological and social problem as pointed out by psychiatrists, psychologists and educationists. On the one hand, Smartphone addiction affects social interaction between individuals in close proximity to one another (Banjo, Hu and Sundar, 2008). In fact, a lack of face-to-face interaction among people is growing because of Smartphone use. This is not only limited to interaction with strangers but also with family members and friends (Glaser 2007). On the other hand, Smartphone addiction also affects students' academic achievement. Javid, Malik and Gujjar (2011) have emphasized a number of the drawbacks and negative impacts of such technology on students' achievement. Students, they say remain busy with writing and sending useless messages, sending missed calls, listening to music and watching movies in a way that wastes their precious time and money. Additionally, a Smartphone addiction symptom is a lack of concentration among students during class. Smartphones provide free messengers and various kinds of social media applications (which are useful and fun, but also have side effects), which enable students to send free messages and chat wherever they can get Wi-Fi (Wireless Fidelity) access. They keep sending messages even if they have tasks to do or have no urgent matters to talk about. Hence, this research is attempts to determine if Smartphone use affects SQU undergraduates' academic achievement. Moreover, it also aims to provide answers to the following research questions:

1. What are the percentages of Smartphone addiction levels among SQU undergraduates'?

2. What are the symptoms of Smartphone addiction among SQU undergraduates?

3. What are the mostly addictive Smartphone's activities and applications among SQU undergraduates?

4. Is there a significant difference in Smartphone addiction among SQU undergraduate' students related to their academic achievement?

5. Are there significant differences in Smartphone addiction among SQU undergraduates related to the following demographic variables: Gender, field of study, parents educational level, family income level.

\section{Related Literature}

Terms such as "Smartphone addiction" (Casey, 2012; Kwon et al., 2013), "mobile phone addiction" (Abu-Jedy, 2008; Ahmed et al., 2011; Hong et al., 2012; Pawłowska and Potembska, 2011; Park, 2005; Szpakow, Stryzhak and Prokopowicz, 2011), "problematic mobile phone use" (Billieux, Linden and Rochat, 2008; Krajewska-Kułak et al., 2012; Takao et al., 2009), "mobile phone dependence" (Chóliz, 2012; Satoko, Masahiro, Kimio, Aki and Kanehisa, 2009), "compulsive mobile phone use" (Hassanzadeh and Rezaei, 2011; Matthews, Pierce and Tang, 2009) and "mobile phone overuse" (Perry and Lee, 2007), have all been used to describe more or less the same concept, that is, individuals could be so engrossed in their Smartphone use to the extent that they neglect other areas of their life. The most commonly used terms to describe this kind of addiction are "mobile phone addiction" and recently "Smartphone addiction". This study uses the latter term.

Nevertheless, there is no consensus among the previous studies regarding the definition of Smartphone addiction because of: a) The variety of addiction symptoms that are associated with Smartphone use; b) The wide variety of Smartphone new functions; c) The different problematic outcomes that are associated with Smartphone addiction (Takao et al., 2009). However, in contrast to material-related addictions, Smartphone addiction may not produce observable signs or symptoms, such as physiological indications of cravings and the addicted individual may appear to be working in a normal and socially acceptable manner (Griffiths, 1996; Lemon, 2002). For Griffiths (1999) and Shaffer (1996), technological addictions involves extreme human-machine interactions which are developed when people become dependent on the device to reduce the negative mood states or to increase the positive consequences.

\subsection{Smartphone Addiction Among University Students}

In one of the earliest studies on mobile phone addiction, Bianchi and Phillips (2005) argued that the problem of mobile phone use may be a symptom of an impulse control deficit or depression. Their study addressed the underlying problem as well as inappropriate mobile phone use. They used some dependent variables to predict mobile phone addiction, such as reported time per week spent using the mobile phone, mobile phone problem use, reported percentage of use that is socially based, reported percentage of use that is business based. Other variables were also considered including reported percentage of use in other features. The results indicated that the technological addictions offer an appropriate starting point for a consideration of problem mobile phone use. The results also revealed that young people, in particular, appear to be susceptible to high use and problem use. They were the heaviest users of the SMS function and other features of mobile phones.

James and Drennan (2005) carried out research on Australian university students' mobile phone use and discovered a large use rate of 1.5-5 hours a day. Their findings showed a range of characteristics associated with addictive use. These were: impulsiveness, mounting tension prior to using the device, failure of control strategies and withdrawal symptoms. The results also identified some factors that correlated with consumer engagement in addictive or compulsive behavior. Situational factors affecting excessive use included special events, alcohol abuse and depressive circumstances. A wide range of other negative consequences from mobile phone addiction among consumers included financial issues, damaged relationships, emotional stress and falling literacy For Perry and Lee (2007), symptoms related to mobile phone addiction were found to be prevalent among Mauritius University students. Between $6 \%$ and $11 \%$ of students showed addiction symptoms related to tolerance, withdrawal, displacement of attention to school or work and the inability to diminish use. The number of messages sent and the perceived skill at using SMS were significant predictors of mobile 
phone addiction among students. Among the small percentage who revealed symptoms of addiction, use of text messaging was double to triple compared to the one found in the rest of the population sample studied.

Walsh et al. (2008) carried out a qualitative research to examine activities of university students regarding mobile phone usage. They also sought to establish addictive facts by using Brown's (1997) behavioral addiction criteria. Symptoms of behavioral and cognitive salience, conflict with other activities, euphoria, tolerance, withdrawal and relapse and reinstatement emerged at varying levels amongst participants' descriptions of their mobile phone use. The study concluded that university students were addictive to using mobile phone to an extent that they revealed the indication of behavioral obsession.

In another study, Walsh, White and Young (2010) examined the effects of involvement with mobile phone use on their use by people. The results revealed that a high frequency of mobile phone use differed from involvement with mobile phones as the association with frequency of use was relatively small (.30). The predictors of each behavior differed too. Measures of frequency of mobile phone use generally assess the number of times a day people use their phone for calls or text messages because many check their phone for missed messages or calls without actually using it. Self-identity and validation from others were explored as predictors of both types of mobile phone behavior. However, only self-identity predicted frequency of use, while both self-identity and validation from others predicted mobile phone involvement. Hassanzadeh and Rezaei (2011) defined text-message dependency as text-messaging-related compulsive behavior that causes psychological or behavioral symptoms resulting in negative social outcomes. Their study particularly focused on the relationship between psychosocial factors and psychological or behavioral symptoms, emerging from the process of text-message use among students. The findings showed that students have SMS addiction. The study concluded that SMS addiction has currently become a serious mental and health problem among university students. Moreover, problematic mobile phone use may complicate physiological and psychological problems.

To measure mobile phone addiction, Park (2005) asked respondents to report their minutes of mobile phone use and divided them into light user and heavy user categories. Respondents who reported less than nine minutes of use were considered "light" users, while respondents who reported more than nine minute of use were considered "heavy" users. Mobile phone addiction was measured based on seven criteria of dependency. These were: tolerance, withdrawal, unintended use, cutting down, time spent, displacement of other activities and continued use. The results showed that mobile phone users grew tolerant of mobile phones despite the fact that they might cause such problems as high phone bills and public annoyance. Also, when the mobile phone was unavailable for a time, users became highly anxious and irritated. This behavior continued although these were troubling signs of addiction.

Likewise, Chóliz (2012) designed a questionnaire to evaluate mobile phone dependence in adolescents. This was based on criteria from the Diagnostic and Statistical Manual for Mental Disorders-Fourth Edition-Text Revision (DSM-IV- TR). These criteria included excessive use, problems with parents, difficulty in controlling use, interference with other activities and emotional discomfort when the mobile phone could not be used. The questionnaire consisted of three factors: Lack of Control/Problems, Tolerance/Interference and Abstinence. The results showed that with regard to gender and the age of the participants, girls had a higher degree of dependence on mobile phones than boys. Likewise, girls scored higher than boys on each of the factors in the questionnaire. They had higher levels of tolerance and experienced more interference with other activities. They were more likely to use mobile phones to avoid uncomfortable mood states and they felt bad if they could not use their phones. They also had greater economic and family problems as a result of costs associated with mobile phone use. Billieux et al. (2008) studied the role of impulse in actual and problematic use of mobile phones. They reported four different components associated with impulsive behavior which were urgency, lack of premeditation, lack of perseverance and sensation seeking. The Problematic Mobile Phone Use Questionnaire (PMPUQ) measured four different dimensions of problematic use. These were: prohibited use, dangerous use, dependence, and financial problems. The results showed that, although each kind of impulse played a specific role in mobile use, "urgency" appeared to be the strongest predictor of problematic use.

In Japan, Igarashi, et al. (2008) investigated how self-perception of text message dependency leads to psychological/behavioral symptoms among university students. They used a self-report questionnaire to measure the frequency of text messages, self-perception of text message dependency and psychological/behavioral symptoms. Selfperception of text-message dependency comprised three factors: perception of excessive use, emotional reaction and relationship maintenance. The findings showed that message frequency was significantly related to psychological/behavioral symptoms. Also, self-perception of text message dependency strongly affected psychological/ behavioral symptoms.

Abu-Jedy (2008) explored mobile phone addiction and its relationship with self-disclosure among university students in Jordan. The study also investigated the characteristics of addicted students, the main aspects of mobile phone addiction, the purposes of mobile use and the time spent in using them. The results revealed that addicted students comprised $25.8 \%$ of the total sample. The percentage of addicted females was found to be twice that of males. There was also a higher level of addiction among private university students than public ones.

Hooper and Zhou (2007) explored the various types of behavior associated with mobile use. Six possible kinds arising from underlying motives were identified among university students. These were: addictive, compulsive, habitual, dependent, mandatory and voluntary behavior. A survey was conducted to test these categories. Findings indicated that mandatory behavior was the strongest type of use, while addictive behavior was the weakest. The result also showed that 
mobile phone use could be regarded more as mandatory, voluntary or dependent behavior than habitual, compulsive or addictive.

Another study, by Takao et al. (2009), examined the correlation between problematic mobile phone use and some personality characteristics among university students. Separate multiple regressions were carried out for each dependent variable to determine whether they could be predicted from the independent variables. The predictor variables included gender, self-monitoring, approval motivation and loneliness. The dependent variables included the reported time per week spent using a mobile phone, the reported number of people with whom participants talk regularly, the reported time per week spent writing and reading text messages and the reported number of people with whom participants exchange text messages regularly. The findings indicated that problematic mobile phone use was a function of gender, self-monitoring and approval motivation but not of loneliness. These findings suggest that the measurements of these addictive personality characteristics would be helpful in terms of screening and intervention.

Satoko et al. (2009) carried out a study to clarify the relationship of personality and lifestyle to mobile phone dependence. They defined this dependence as an intermittent craving to use these phones or excessive use of them. The results of multiple regression analysis indicated that scores for extroversion and neuroticism were positively related to the score from the Mobile Phone Dependence Questionnaire (MPDQ), while the score for healthy practices was negatively related to that of the MPDQ. The findings also suggested that mobile phone dependence in female college students was associated with high traits of sociability and neuroticism as well as an unhealthy lifestyle.

In Pakistan, Ahmed, Ramzan, Qaziand and Jabeen (2011) explored the pattern of mobile phone use among university students to delineate the extent of addictive behavior in its usage. Findings revealed that most students were able to set definite priorities for their responsibilities and commitments and their mobile phone use. Their results also revealed that very few students $(4.8-18.5 \%)$ always exhibited extreme addictive behavior. Thus, they concluded that university students used their mobile phones within reasonable limits and did not move towards extreme behaviors that lead to addictive mobile phone use.

By contrast, Belarusian, Szpakow, et al. (2011) assessed the role of mobile phones in students' lives and evaluated the mobile phone addiction symptoms among university students. The results indicated that almost $1 / 10$ of the students had symptoms of such addiction and thus $68.8 \%$ were convinced of the harmful effects of mobile phones. Nearly $1 / 3$ believed that mobile phones should be switched off in a theatre (30\%) and in a church (33.8\%). Some $28.8 \%$ knew the definition the monophobia. Most, (71.9\%) had never switched off their phones.

In Taiwan, Hong et al. (2012) investigated the relationship between psychological characteristics, mobile phone addiction and the use of mobile phones among female university students. The result showed that social extraversion and anxiety had positive effects on addiction while self-esteem had negative effects. Also mobile phone addiction had a positive predictive effect on mobile phone use behavior. The results revealed too, that female university students with mobile phone addiction would make more phone calls and send more text messages. Males did.

In China, Casey (2012) identified addiction symptoms that were uniquely associated with Smartphone use among university students. Exploratory factor analysis of the Smartphone Addiction Scale identified five symptoms which were: disregard of harmful consequences, preoccupation, inability to control craving, productivity loss and feeling anxious and lost. The results showed that the higher one scored on loneliness and shyness counts, the higher the likelihood one would be addicted. The study also found that the Smartphone addiction symptoms were significantly and negatively related to the level of face-to-face communication and positively related to present absence. Furthermore, the most powerful factors that affected bonding social capital were gender, grade and loneliness; while the most powerful factor affecting bridging social capital was face-to-face communication with friends.

Krajewska-Kułak et al. (2012) examined the role of having a mobile phone in the students' lives, signs of addiction and whether there were differences in using phones between the Polish and Belarusian students. The results showed that most students had mobile phones. They usually used them for sending text messages, taking photos and accessing the Internet. Of the Polish students $35.2 \%$ and $68.8 \%$ Belarusian were convinced of the harmful effects of mobile phone use. However, more respondents from Poland than Belarus knew that mobile phone users could become addicted. Almost $1 / 5$ of Polish students and 1/10 Belarusian had the symptoms of mobile phone addiction.

Shambare, Rugimbana and Zhowa (2012) argued that the mobile phone has become the 21st century's icon. Their study described mobile phone use as addictive, compulsive and habitual, indeed possibly the biggest non-drug addiction of the 21 st century. The study concluded that university students were among the heaviest users of mobile technologies.

In Korea, Kwon et al. (2013) developed the first scale of Smartphone addiction. It is a self-diagnostic scale based on the Korean self-diagnostic program for Internet addiction that can distinguish Smartphone addicts. Subjects were divided into three groups: a high-risk group, a low- to medium-risk group and the general group. Findings showed that Smartphone addiction rates of the high- risk group and low-to medium-risk group were 2.2 and $9.3 \%$ respectively in adolescents and 1.0 and $6.7 \%$ in adults. Based on factor analysis results, the subscale for the Smartphone Addiction Scale (SAS) was divided as follows: Daily-life disturbance, positive anticipation, withdrawal, cyberspace-oriented relationship, overuse and tolerance.

In Oman, although no previous studies have been conducted on mobile phone addiction, Belwal and Belwal (2009) analyzed mobile phone usage among university students. The results revealed that these students spent more than 10 
Omani Rials per month on mobile services, made less than 10 calls but more than 10 SMS daily. They also depended on their parents for payment of their bills. It was also significantly found that students had a preference for expensive models. They felt uncomfortable without their mobile phones, so they kept them switched on 24 hours a day.

\subsection{Factors influencing Smartphone use and addiction}

Since this study aims to explore the factors influencing Smartphone addiction, such as gender, field of study, parents educational level and family income level among university students, the following section discusses these factors:

\subsubsection{Gender Differences In Smartphone Use And Addiction}

A theme of interest for many researchers relates to gender differences in Smartphone addiction. There is no agreement on which group is at the higher risk of addiction, some studies have revealed gender-related differences. Turner, Love and Howell (2008) suggest that "user personality and individual attributes such as age and gender were found to be differentially associated with some aspects of phone-related behaviors" (p. 1).

Billieux et al. (2008) tested gender differences in both teams of impulsion and problematic mobile phone use among the young. The results showed that men use their mobile phones more frequently in dangerous situations whereas women are more dependent on them. The results on impulsion, showed that men exhibit significantly higher levels of sensation seeking and lower levels of perseverance, while women reveal significantly higher levels of urgency. Walsh et al. (2011) found that gender was associated with mobile phone involvement but not frequency of use. Howell, Love and Turner (2008) investigated gender differences related to their mobile phones and users' perception and attitude towards their use in public and private places. They concluded that while females perceived the service very positively, there was a persistent trend for males to dislike the service, regardless of location.

Similarly, Hakoama and Hakoyama (2011) studied gender differences in multiple aspects of mobile phone use. Their results revealed that females, especially whites, were more likely to depend heavily on their phones to maintain social relationships. Chóliz (2012) found that girls generally used their phones more than boys and also were more likely to engage in phone abuse and experience problems with their parents due to excessive use. Chung (2011) tried to understand the causes of girls' excessive use of mobile phones. He predicted that there would be a close relationship between them and the maintenance of interpersonal solidarity among their adolescent contemporaries. He found that those who had a greater tendency to become addicted sent numerous text messages from places such as schools, where excessive use of mobile phones can be a problem.

However, mobile phones use showed different results in the study by Devís-Devís et al. (2009). They compared girls' and boys' usage and found that boys spent more time on this. They also found that university students used these communication tools more on weekends than on week days. This showed that there were different factors responsible for phone usage. Confirming this, Villella et al. (2011) found that behavioral addiction was more common among boys than girls.

On the other hand, there were also gender differences in user motivation. Pawłowska and Potembska (2011) found that women used their phones more frequently than men to satisfy their need for acceptance and closeness, to establish and sustain social relationships, and to express their emotions. Moreover, women were characterized by a higher severity of addiction to voice calls and text messages than men, who liked to use their phones to listen to music, take photographs, make videos, play games, and connect to the Internet more frequently than women. Likewise, Balakrishnan and Raj (2012) examined the motives of use among Malaysian university students. The results showed that female students used their mobile phones more to socialize, gossip and as a safety device.

Interestingly, Iqbal (2010) divided mobile phone users into three groups-casual, moderate and excessive. At the casual and moderate levels, young adult females had a stronger drive to fulfill their interpersonal motives, but at the excessive level men had greater motivation in nearly all contexts. The results showed that males between 21-23 years in particular made and received more voice calls than girls. As far as text messaging frequency was concerned, males in the $21-23$ age were at the forefront.

Osman, Sabudin, Osman and Shiang-yen (2011) explored the attitude and the behavior of Malaysian consumers towards the such of Smartphone types of use such as application software, e-mail, Internet browsing, ringtones and so on. Their findings indicated that young consumers, especially males, were generally a greater target market. By contrast, female consumers had a higher tendency to adopt or purchase ringtones and wallpapers, which were meant to decorate or personalize their Smartphone. In other words, male consumers seemed to prefer those mobile contents that were practical and useful in fulfilling their information needs.

On the other hand, some studies found that females were more addicted to their phones than males. In one of the most cited studies Bianchi and Phillips (2005) found that tendencies to individual types of mobile phone addiction were mostly gender-related. Indeed, they pointed out that women overused the mobile phone to maintain social relationships more frequently than men, while men used it to make business calls.

Nevertheless, they found no statistically significant differences between men and women in the number of text messages sent. However, Igarashi, Takai and Yoshida, (2005) reported that girls established interpersonal relationships through text messages more often than boys. 
Similarly, Wilska (2003) emphasized that girls overused mobile phones to send text messages and to make phone calls more frequently than boys, who focused more on the stylish looks and technical features of a phone because they were more interested in new technologies. By contrast, Ling (2001) found that during the period between 1997 and 2001 , mobile phones were more often used by boys than girls, as they first treated them as a technical innovation. However, after 2001 girls started to use mobile phones significantly and more frequently than boys, as they became their main tool for developing interpersonal relationships.

According to Geser (2006) while boys were somewhat slower than girls in adopting the mobile phone universally, they tend to use it on the same scale by producing the same monthly bills. In other words, both genders were rather similar in the quantitative intensity of use, but they still differ significantly in the qualitative patterns and purposes of use. In fact, men and women have always been found to maintain quite different attitudes toward mobile phones.

Other studies prove that gender and mobile phone usage are not significantly related. Perry and Lee (2007) found no gender differences for addiction measures among developing world university students, although males were heavier users of text messaging than females.

By contrast, Takao et al. (2009) claimed that gender appeared to be a weak predictor of problematic mobile phone use, though females seemed likely to experience problems more frequently. They argue that cultural or ethnic background might influence this addictive behavior in females. In western countries, gender differentiation is not as severe as that in Asian countries, including Japan, where females inexplicitly still behaved modestly.

In Pakistan, Kamran (2010) investigated university students mobile phone calling and texting patterns. He found that the majority were extremely heavy users especially of text messaging, regardless of gender. Results showed that the average received calls by male students were (4.3) and (4.1) per female students on the diary day. Also, the average number of dialed calls by male students remained (3.9) and by female students (3.4). However, students reported an incredibly high rate of SMS communication on the diary day. The average number of SMS received by a male student remained at (98.4) and by a female (85.7). Similarly, the average number of text messages sent remained almost the same among male and female students. Male students sent (109.5), while female students sent (98.2) on the diary day.

\subsubsection{Smartphone Addiction And Students' Field Of Study}

A few studies have examined the relationship between Smartphone addiction and students' field of study and this one will too.

In reference to this, Abu-Jedy (2008) investigated the addiction to mobile phones and its relationship with self-disclosure among a sample of students selected from the university of Jordan and Amman Al-Ahliyya University. He found that there was a significant difference in terms of addiction related to the students' field of study. Specifically, he found that humanities students of had a higher level of addiction than natural science students. Also, there was a higher level of addiction among a private university students than public university ones.

Likewise, Oliver (2005) studied Australian university students and found that business students used mobile phones very extensively in their courses. Both older and postgraduate students used PDAs even if they had previously not used them, but they were also acutely aware of the technical issues which could accompany their use. Also, Ruiz-Olivares, Lucena, Pino and Herruzo (2010) observed habits related to addictive behavior among university students and its relationship with their macro-field of study (arts/sciences). It would seem that being a science student was a risk factor for gambling addiction and being older and an Arts student were risk factors for shopping addiction. Students showed moderate incidence of mobile phone use behavior, while a very small group came close to having an addiction problem.

Hassanzadeh and Rezaei (2011) explored the effect of students' course on SMS addiction among students of the Islamic Azad University. Results showed that there was a significant difference between SMS addiction among students in different courses or majors.

\subsubsection{Smartphone Addiction And Family Income Level}

According to Castell, Ardevol, Qiu and Sey (2004) users' income is an important predictor of mobile phone use. Income is often a reason for mobile users to either continue or stop using emerging technology. Wireless technology, such as mobile devices, were generally expected to have a higher correlation with income, since these are becoming more advanced and applications are more expensive. Hence, making the assumption that there is a higher adoption of mobile devices in high socio-economic groups.

Similarly, Zulkefly (2009) examined the personal and family factors related to the mobile phone use. The results indicated that family income highly correlated with the duration of phone use and monthly expenditure. In conclusion, the findings revealed that students from higher income families spent more time and money on their mobile phone.

In contrast, research by Brown, Campbell and Ling (2011) found that lower income students' use of their mobile devices for the Internet was significantly higher than with students who had higher family earnings. Precisely, the results showed that in families which earned less than $(\$ 30,000)$ per year, $(41 \%)$ of students used their mobile phones to access the Internet compared to $(23 \%)$ of students in families that earned more than $(\$ 30,000)$ per year. This disparity may exist because lower income students lack access to other information communication technologies, such as PCs and tablets. Consequently, low income students accept mobile phone as an alternative to access the Internet. The results also 
revealed that students who paid their own phone bills used more features and services that the phone offered than students who did not pay their own monthly bills. In fact, $(23 \%)$ of students with low incomes pay their own phone bills and only $(4 \%)$ of students from families with higher incomes

Likewise, Rice and Katz (2003) found that lower income groups in the United States and in developing countries usually used mobile technology before any other users due to the lack of access to other wireless communication technology.

However, James and Drennan (2005) found that university students, regardless of income, had a long established relationship with their phones with an average of 6.5 years. All subjects were using their third to fifth mobile phone upgrade. Moreover, their use time was high, ranging from 1.5 to 5 hours per day and the average bill per month was $\$ 140$, which was expensive given restricted student incomes. In Prezza et al. (2004) the results showed that students with a lower socio-economic status tended to use the mobile phone less to make phone calls. However, there was no significant status difference for the other uses.

Chakraborty (2006) compared usage patterns in a mature market (United States) with a rapidly growing new market (India) by surveying students in each country. The findings showed similarities in the use of phones to communicate with others and in the perception of mobile phone use in public settings, but showed differences in text messaging. However, in a developing market like India, mobile phones may be the primary and only phones to which students have access.

Naz, Khan, Daraz and Hussain (2011) highlighted the economic consequences of excessive mobile phone use among university students. They found that it is one of the disastrous threats to economic independence of students and their families. They deduced that excessive mobile phone use paves the way for plenty of crimes and deviant acts that were regarded as severe threats to the stability of the community. Such crimes include robberies, excess of burglaries and thefts, and more prominently, the curse of gambling.

\subsubsection{Smartphone Addiction And Parent Education Level}

A new report published by Grunwald Associates and the Learning First Alliance (2013) found that in terms of support, a majority of parents believed that mobile phones could be positive educational tools for their children because their applications offer engaging ways of learning, in addition to connecting and communicating. This report states that "when it comes to mobile devices and education, most parents believe (completely or somewhat) that these devices open up learning opportunities (71 percent), benefit students' learning (62 percent) and engage them in the classroom (59 percent). Thirty-nine percent of parents say that using mobile devices supports their child's learning regardless of the app used." (Grunwald Associates LLC., 2013. P. 15).

However, Zulkefly (2009) found that parents' education level was positively related to the monthly phone expenditure of university students in Malaysia. This study also found a significant correlation between parents' age and problematic phone use. These findings tend to suggest that students with younger parents were inclined to get hooked on their phones.

By contrast, Ahn (2011) examined the relationship between parents' education and university students' participation in social network sites using phones. The results suggested that parents' education was not a significant predictor of social networking site (SNS) use. Those students appeared to find a way to get connected.

Therefore, Koutras (2006) revealed that due to changes in family structure, many university students are taking more and more responsibility for their families' mobile phone purchase decisions. In cases where both parents work full-time, university students often made mobile phones purchasing decisions in order to compensate for their parents' absence from home. In the case of a single-parent family, they usually had to act on behalf of an absent parent.

\section{Research Methodology}

The data were collected through a questionnaire on Smartphone addiction using a sample of (140) undergraduate students at Sultan Qaboos University (37.1\% male, 62.9\% female). This questionnaire was adapted and modified from those in: (Flanagin, 2005; Walsh, 2009; Casey, 2012; Grellhesl and Punyanunt-Carter, 2012). It included a five- point Likert-type scale. Alpha Cronbach for this questionnaire was $(0,764)$. It explored the level of Smartphone addiction through three parts: the level of Smartphone use, the uses of Smartphones' different activities and applications, and Smartphones' addiction symptoms, as follows:

\subsection{Level of Smartphone Use}

Five questions regarding Smartphone use including the average number of calls sent, calls received, texts sent and texts received every day to measure the level of use (e.g. "How many calls would you make on your mobile phone per day?").

\subsection{Uses of Smartphone}

Seventeen items were included to cover different Smartphone activities and use activities (e.g., How often do you use your mobile phone to do the following: Watch videos, vote on a television programs/enter a competition, set an alarm/reminder, use the calculator, take photos, ....etc.). 


\subsection{Smartphone Addiction Symptoms}

Seventeen items were included to cover the symptoms of Smartphone use distributed in a five-factor of Smartphone addiction profile as identified by Casey (2012). These factors were: disregard of harmful consequences (items: 1, 2, 3, 4), preoccupation (items: 7, 9, 10), inability to control craving( items: 5, 6, 11, 12), productivity loss (items: 13, 14, 15) and feeling anxious and lost (items: 8, 16, 17).

\section{Results}

\subsection{The Levels of Smartphone Addiction Among SQU Undergraduate Students}

This study will measure the level of Smartphone addiction among SQU undergraduates by assessing three addiction criteria : 1) The amount of time they allocate for the use of Smartphones, including calls sent, calls received, messages send, messages received. 2) The frequency of appearance of Smartphone addiction symptoms. 3) The amount of money spent on the performance of a number of activities through the use of Smartphones. Based on the overall average, addiction was classified into three levels (casual, moderate and heavy), see table (1).

Table 1. The percentages of smartphone addiction levels' among SQU undergraduate students

\begin{tabular}{|c|c|c|c|c|c|c|c|c|}
\hline \multicolumn{2}{|c|}{ Addiction levels } & \multicolumn{6}{|c|}{ Smartphone Addiction Criteria } & \multirow{2}{*}{$\begin{array}{r}\text { The avarage } \\
59.3\end{array}$} \\
\hline Casual & Frequency & $\begin{array}{c}\begin{array}{l}\text { Money } \\
\text { spent }\end{array} \\
100\end{array}$ & $\begin{array}{c}\begin{array}{l}\text { Calls } \\
\text { sent }\end{array} \\
123\end{array}$ & $\begin{array}{l}\begin{array}{l}\text { Calls } \\
\text { Received }\end{array} \\
113\end{array}$ & $\begin{array}{c}\begin{array}{l}\text { Messages } \\
\text { sent }\end{array} \\
8\end{array}$ & $\begin{array}{c}\begin{array}{l}\text { Messages } \\
\text { received }\end{array} \\
6\end{array}$ & $\begin{array}{c}\begin{array}{l}\text { Addiction } \\
\text { symptoms }\end{array} \\
6\end{array}$ & \\
\hline & Percentage & $71.4 \%$ & $87.9 \%$ & $80.7 \%$ & $5.7 \%$ & $4.3 \%$ & $4.3 \%$ & $42.3 \%$ \\
\hline \multirow[t]{2}{*}{ Moderate } & Frequency & 32 & 14 & 23 & 19 & 10 & 127 & 37.5 \\
\hline & Percentage & $22.9 \%$ & $10 \%$ & 16.45 & $13.6 \%$ & $7.1 \%$ & $90.7 \%$ & $26.8 \%$ \\
\hline \multirow[t]{2}{*}{ Heavy } & Frequency & 8 & 3 & 4 & 113 & 124 & 7 & 43.2 \\
\hline & Percentage & $5.7 \%$ & $2.15 \%$ & $2.8 \%$ & $80.7 \%$ & $88.6 \%$ & $5 \%$ & $30.8 \%$ \\
\hline \multirow[t]{2}{*}{ Total } & Frequency & 140 & 140 & 140 & 140 & 140 & 140 & 140 \\
\hline & Percentage & $100 \%$ & $100 \%$ & $100 \%$ & $100 \%$ & $100 \%$ & $100 \%$ & $100 \%$ \\
\hline
\end{tabular}

The results in Table (1) reveal that the casual level of Smartphone addiction was the most frequent (42.3\%), followed by the heavy level (30.8\%) and finally the moderate level $(26.8 \%)$.

\subsection{The Symptoms of Smartphone Addiction Among SQU Undergraduates}

Table 2. Means and std. deviation of smartphone addiction factors

\begin{tabular}{l|c|c}
\hline The factors of Smartphone addiction symptoms & Mean & Std. Deviation \\
\hline Disregard Of Harmful Consequences & 3.74 & .75 \\
\hline Productivity Loss & 3.49 & .95 \\
\hline Inability To Control Craving & 3.19 & .94 \\
\hline Preoccupation & 3.17 & 1.79 \\
\hline Feeling Anxious and Lost & 3.14 & 1.06 \\
\hline
\end{tabular}

The results in Table (2) identify five factors for Smartphone addiction symptoms among SQU undergraduates. These include disregard of harmful consequences (3.74), productivity loss (3.49), inability to control craving (3.19), preoccupation (3.17) and feeling anxious and lost (3.14). "Disregard of harmful consequences" had the highest mean, while "feeling anxious and lost" had the least.

\subsection{The Most Addictive Smartphone Activities And Applications By SQU Undergraduates}

Table 3. The means and std. deviation of smartphone activities and applications uses among SQU undergraduates

\begin{tabular}{l|c|c}
\hline \multicolumn{1}{c|}{ Smartphone activities and applications } & Mean & Std. Deviation \\
\hline Sent messages (SMS $\backslash$ WhatsApp) & 4.53 & .79 \\
\hline
\end{tabular}




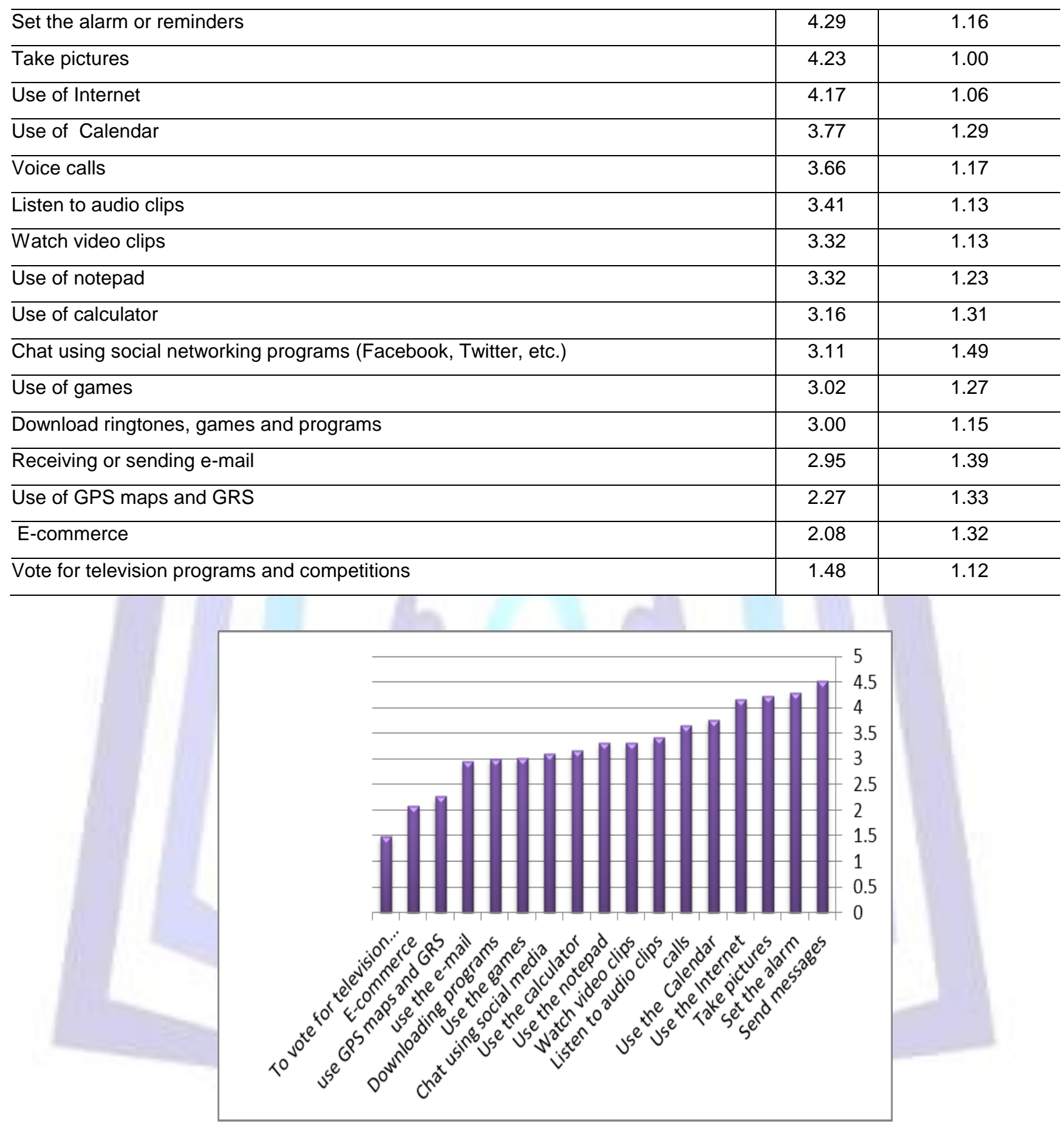

Fig.1. Smartphone use activities among SQU undergraduates

The results in Table(3) and Figure (1) show that sending messages was the most addictive Smartphone activity among SQU undergraduates (4.53), while voting for television programs and competitions messages was the least addictive (1.48).

5.4 The Impact Of Smartphone Addiction Among SQU Undergraduates On Their Academic Achievement

Table 4. Means and std. deviation of smartphone addiction among SQU undergraduates related to their academic achievement

\begin{tabular}{|c|c|c|c|c|c}
\multicolumn{2}{|c|}{$\begin{array}{c}\text { High achievement } \\
(\mathbf{n = 1 1 )}\end{array}$} & \multicolumn{2}{|c|}{$\begin{array}{c}\text { Middle achievement students } \\
(\mathbf{n}=76)\end{array}$} & \multicolumn{2}{|c}{ low achievement students $(\mathbf{n}=22)$} \\
\hline $\mathrm{M}$ & $\mathrm{S}$ & $\mathrm{M}$ & $\mathrm{S}$ & $\mathrm{M}$ & $\mathrm{S}$ \\
\hline
\end{tabular}




\begin{tabular}{c|c|c|c|c|c|c}
\hline $\begin{array}{c}\text { Smartphone } \\
\text { addiction }\end{array}$ & 3.51 & .47 & 3.42 & .79 & 3.42 & .79 \\
\hline
\end{tabular}

Table 5. One-Way ANOVA results of smartphone addiction among SQU undergraduates related to their academic achievement

\begin{tabular}{c|c|c|c|c|c}
\hline & Sum of Squares & Df & Mean Square & F & Sig. \\
\hline Between Groups & .104 & 2 & .052 & .085 & \\
\hline Within Groups & 64.988 & 106 & .613 & \\
\hline Total & 65.091 & 108 & & \\
\hline
\end{tabular}

The results of one-way ANOVA in Tables (4) and (5) reveal that there were no significant differences in Smartphone addiction among SQU undergraduates' academic achievement.

5.5 The Differences In Smartphone Addiction Among SQU Undergraduates Related To The Following Demographic Variables: Gender, Field Of Study, Parents' Educational Level And Family Income Level.

Table 6. Gender differences in smartphone addiction among SQU undergraduates

\begin{tabular}{l|c|c|c|c|c|c}
\hline \multirow{2}{*}{} & \multicolumn{2}{|c|}{ Male (n=51) } & \multicolumn{2}{c|}{ Female (n=88) } & \multirow{2}{*}{ "T" vale } & \multicolumn{2}{c}{ Significant } \\
\cline { 2 - 5 } & $\mathrm{M}$ & $\mathrm{S}$ & $\mathrm{M}$ & $\mathrm{S}$ & & \\
\hline Smartphone addiction & 3.49 & 0.91 & 3.29 & 0.66 & 1.5 & $0.03^{\star}$ \\
\hline
\end{tabular}

$\mathrm{M}=$ means, $\mathrm{s}=$ Std. Deviation * significant at the 0.05 level

The results in Table (6) reveal that there were significant gender differences in Smartphone addiction among SQU undergraduates. For example, males were more addicted to Smartphone use than females.

Table 7. The differences in smartphone addiction among SQU undergraduates related to the field of study

\begin{tabular}{|c|c|c|c|c|c|c|}
\hline & \multicolumn{2}{|c|}{$\begin{array}{l}\text { Physical Science } \\
\text { colleges }(n=85)\end{array}$} & \multicolumn{2}{|c|}{$\begin{array}{c}\text { Social Science and } \\
\text { Humanities colleges }(n=54)\end{array}$} & \multirow[t]{2}{*}{$\begin{array}{l}\text { "T" } \\
\text { vale }\end{array}$} & \multirow[t]{2}{*}{ significant } \\
\hline & $\mathrm{M}$ & S & $\mathrm{M}$ & S & & \\
\hline Smartphone addiction & 3.37 & 0.71 & 3.34 & 0.84 & 0.02 & 0.23 \\
\hline
\end{tabular}

The results in Table (7) demonstrate that there were no significant differences in Smartphone addiction among SQU undergraduates related to the field of study.

Table 8. Means and std. deviation of smartphone addiction among SQU undergraduates related to fathers' education level

\begin{tabular}{l|c|c|c|c|c|c}
\hline \multirow{2}{*}{} & \multicolumn{4}{|c}{ Fathers' education level } \\
\cline { 2 - 7 } & \multicolumn{2}{|c|}{ High $(\mathrm{n}=23)$} & $\mathrm{S}$ & \multicolumn{2}{c}{ Low $(\mathrm{n}=69)$} \\
\cline { 2 - 7 } & $\mathrm{M}$ & $\mathrm{S}$ & $\mathrm{M}$ & $\mathrm{S}$ & $\mathrm{M}$ & $\mathrm{S}$ \\
\hline Smartphone addiction & 3.41 & .66 & 3.36 & .71 & 3.36 & .83 \\
\hline
\end{tabular}

Table 9. One-Way ANOVA results of smartphone addiction among SQU undergraduates related to fathers' education level

\begin{tabular}{l|c|c|c|c|c}
\hline & Sum of Squares & Df & Mean Square & F & Sig. \\
\hline Between Groups & .046 & 2 & .023 & .038 & .963 \\
\hline Within Groups & 79.769 & 133 & .600 & \\
\hline Total & 79.814 & 135 & & \\
\hline
\end{tabular}

The results in Tables (8) and (9) reveal that there were no significant differences in Smartphone addiction among SQU undergraduates related to fathers' education level. 
Table 10. Means and std. deviation of smartphone addiction among SQU undergraduates related to mothers' education level

\begin{tabular}{l|c|c|c|c|c|c}
\hline \multirow{2}{*}{} & \multicolumn{9}{|c}{ Mothers' education level } \\
\cline { 2 - 7 } & \multicolumn{2}{|c|}{ High $(\mathrm{n}=12)$} & \multicolumn{2}{c}{ Middle level $(\mathrm{n}=24)$} & \multicolumn{2}{c}{ Low (n=98) } \\
\cline { 2 - 7 } & $\mathrm{M}$ & \multicolumn{2}{|c|}{ SD } & M & SD & \multicolumn{2}{c}{ M } & SD \\
\hline Smartphone addiction & 3.06 & .74 & 3.30 & .66 & 3.43 & .80 \\
\hline
\end{tabular}

Table 11. One-way ANOVA results of Smartphone addiction among SQU undergraduates related to mothers education level

\begin{tabular}{l|c|c|c|c|c}
\hline & Sum of Squares & Df & Mean Square & F & Sig. \\
\hline Between Groups & 1.550 & 2 & .775 & 1.296 & .277 \\
\hline Within Groups & 78.324 & 131 & .598 & \\
\hline Total & 79.874 & 133 & & & \\
\hline
\end{tabular}

The results of One-way ANOVA, as reflected by tables (10) and (11), revealed that there were no significant differences in Smartphone addiction among SQU undergraduates related mothers education level.

Table 12. Means and std. of deviation of smartphone addiction among squ undergraduates related to family income level

\begin{tabular}{l|c|c|c|c|c|c}
\hline & \multicolumn{2}{|c|}{$\begin{array}{c}\text { High income level } \\
\text { students }(\mathbf{n}=15)\end{array}$} & \multicolumn{2}{c|}{$\begin{array}{c}\text { Middle income level } \\
\text { students }(\mathbf{n}=117)\end{array}$} & \multicolumn{2}{c}{$\begin{array}{c}\text { Low income level students } \\
(\mathbf{n}=7)\end{array}$} \\
\cline { 2 - 7 } & $\mathrm{M}$ & $\mathrm{SD}$ & $\mathrm{M}$ & $\mathrm{SD}$ & $\mathrm{M}$ & SD \\
\hline Smartphone addiction & 3.09 & .94 & 3.40 & .71 & 3.31 & 1.21 \\
\hline
\end{tabular}

Table 13. One-way ANOVA results of smartphone addiction among SQU undergraduates related to family income level

\begin{tabular}{l|c|c|c|c|c}
\hline & Sum of Squares & Df & Mean Square & F & Sig. \\
\hline Between Groups & 1.263 & 2 & .631 & & \\
\hline Within Groups & 80.337 & 136 & .591 & \\
\hline Total & 81.599 & 138 & & & \\
\hline
\end{tabular}

The results in Tables (12) and (13) revealed that there were no significant differences in Smartphone addiction among SQU undergraduates related to family income level.

\section{Discussion Of Results}

One of the major aims of this research was to measure the level of Smartphone addiction among SQU undergraduates by assessing three addiction variables: 1) The amount of time they allocate to the use of Smartphones, including calls sent, calls received, messages sent, messages received; 2) The frequency of appearance of Smartphone addiction symptoms; 3)The amount of money they spend on the performance of a number of activities through the use of Smartphones. Based on the overall average, addiction was classified into three levels (casual, moderate and heavy). Specifically, the results indicate that the casual level of Smartphone addiction was the most frequent level (42.3\%), followed by the heavy level (30.8\%) and finally the moderate level $(26.8 \%)$. The results also reveal that at the casual level of Smartphone addiction the SQU undergraduates spend (1-10) Omani Ryal (OR) on their phone monthly, send and receive (1-4) calls and messages daily and show the least level of addiction symptoms. At the moderate level of Smartphone addiction they spend (11-20) OR. on their phone monthly, send and receive (8-10) calls and messages daily and show a moderate level of addiction symptoms. But at the heavy level of Smartphone addiction they spend more than 20 OR. on their Smartphone monthly, send and receive more than 10 calls and messages daily and showed the highest level of addiction symptoms.

This result shows that the majority of students were not frequently involved in heavy addictive use patterns. In other words, SQU students use their Smartphones within reasonable limits and do not tend towards extreme behavior leading to heavy addictive Smartphone use. However, the $30.8 \%$ of heavy addiction students to Smartphones among SQU can be explained by the fact that Smartphones increase students social communication and expand their opportunities for making 
social relationships. This finding is further supported by the fact that Smartphones are equipped with various features that facilitate communication and entertainment for their users. These results agree with those revealed by previous studies (Ahmed et al., 2011; Szpakow et al., 2011; Krajewska-Kułak et al., 2012).

The results also identified five factors for Smartphone addiction symptoms among SQU undergraduates including disregard of harmful consequences (3.74), productivity loss (3.49), inability to control craving (3.19), preoccupation (3.17); and feeling anxious and lost (3.14)."Disregard of harmful consequences" had the highest mean, while "feeling anxious and lost" had the lowest. These results agree with those revealed by previous studies (Casey, 2012; Szpakow et al., 2011).

Sending messages was the most addictive Smartphone activity among SQU undergraduates. This can be attributed to the fact that texts can be composed and sent in a short time from virtually anywhere. University students prefer text messaging because the service is quick, cheap and convenient. They also use text messaging to coordinate with both friends and family. These results agree with those revealed by previous studies (Hassanzadeh and Rezaei, 2011; Igarashi. et al, 2008) which found that the most popular feature used among the young users was text messaging.

Although more studies have correlated Smartphone addiction with a decrease in academic achievement (e.g. Aoki and Downes, 2003; Hong et al., 2012; Javid, Malik and Gujjar, 2011; Kubey, Lavin and Barrows, 2001; Pierce and Vaca, 2008; Rau et al., 2008; Rodrigues, 2011; Sheereen and Rozumah, 2009; Srivastava, 2005; Szpakow et el., 2011; Sung and Mayer, 2012), our results reveal that there are no significant differences in Smartphone addiction among SQU undergraduates related to their academic achievement. This may be due to their skills in time management and an ability to balance their personal and practical life when they use their Smartphones. Besides, it seems that Smartphone addicts grow tolerant and become very anxious and irritated despite the fact that their addiction may cause other problems, such as a decrease in their academic achievement.

These results also reveal that there were significant gender differences in Smartphone addiction among SQU undergraduates. Males were more addicted than females. This can be attributed to the fact that males send and receive more voice calls and text messages than females. They are also heavier users of Smartphones for pleasure seeking than females. These findings agree with those of other studies (Devís-Devís et al., 2009; lqbal, 2010; Villella et al. 2011) which showed that males in particular, made and receive more voice calls and text messages than females.

The results of the study indicate that there were no significant differences in Smartphone addiction among SQU undergraduates related to the field of study. This result can be attributed to the fact that SQU students from different fields of study tend to use their Smartphones with equally when they feel a need for information to write their term papers and assignments. Therefore, it seems that both groups were similar in their use regardless of their field of study. This result differs from that of Abu-Jedy (2008) who found that humanities students had a higher level of addiction than natural science students.

The results of the study also show that there were no significant differences in Smartphone addiction among SQU undergraduates related to parents educational level and family income level. These findings agree with those of other studies, such as James and Drennan (2005) and Chakraborty (2006) which revealed that both groups were similar in their use regardless of their parents income and education. They also agreed with those of Ahn (2011), which suggested that parents' education was not a significant predictor of SNS use through mobile phones. However, these findings differ from those of other studies such as those of Castell et al. (2004) and Zulkefly (2009), which found that students from higher income families spent more time and money on their mobile phone. They also differ from other studies, such as those of Brown et al. (2011), and Rice and Katz (2003), which found that lower income students used their mobile phones more heavily.

\section{ACKNOWLEDGMENTS}

The conducting of this study was possible thanks to the generous financial support of the Omani Research Council (TRC)

\section{REFERENCES}

[1] Abu-Jedy. A. 2008. Mobile Phone Addiction And Its Relationship With Self-Discloser Among Sample Of Students From University Of Jordan And Amman Al-Ahliyya University. Jordan Journal of educational science. 4(2), $137-150$.

[2] Ahmed, I., Qazi, T. and Perji, K. 2011. Mobile Phone To Youngsters: Necessity Or Addiction. African Journal of Business Management. 5(32), 12512-12519.

[3] Ahmed, I., Ramzan. M., Qazi, T. F. , and Jabeen, S. 2011. An Investigation Of Mobile Phone Consumption Patterns Among Students And Professionals; Is There Any Difference? European Journal of Economics, Finance And Administrative Sciences. 39,136-143.

[4] Aoki, K., and Downes, E. J. 2003. An Analysis Of Young People's Use Of And Attitudes Toward Cell Phones. Telematics and Informatics. 20, 349-364.

[5] Balakrishnan, V. ,and Raj, R. J. 2012. Exploring The Relationship Between Urbanized Malaysian Youth And Their Mobile Phones: A Quantitative Approach. Telematics and Informatics. 29, 263-272. 
[6] Banjo, O., Hu, Y., and Sundar, SH. S. 2008. Cell Phone Use and Social Interaction with Proximate Others: Ringing in a Theoretical Model. The Open Communication Journal. 2, 127-135 127.

[7] Belwal, R.; Belwal, S. 2009. Mobile Phone Use Behavior of University Students in Oman. New Trends in Information and Service Science. 2009. NISS '09. International Conference. pp.954-962, June 30 2009-July 2 2009. doi: 10.1109/NISS.2009.65

[8] Bianchi, A., and Phillips, J. 2005. Psychological Predictors Of Problem Mobile Phone Use. Cyber Psychology and Behavior. 8, (1), 39-51.

[9] Billieux, J. ,Linden, M. , and Rochat, L. 2008. The Role of Impulsivity in Actual and Problematic Use of the Mobile Phone. Applied Cognitive Psychology. 22, 1195-1210.

[10] Bouazza, A. 2001. Use Of The Internet By Students At Sultan Qaboos University. King Fahad National Library Journal. 6 (2), 91-115.

[11] Brown, K., Campbell, S.W., Ling, R. 2011. Mobile Phones Bridging the Digital Divide for Teens in the US? Future Internet. 3, 144-158; doi:10.3390/fi3020144

[12] Brown, R. I. F. 1997. A Theoretical Model Of The Behavioral Addictions - Applied To Offending. In J. E. Hodge, M. McMurran and C. R. Hollin (Eds.), Addicted to crime. Chichester, UK: John Wiley.

[13] Casey, B. M. 2012. Linking Psychological Attributes To Smartphone Addiction, Face-To-Face Communication, Present Absence And Social Capital. Unpublished Master's thesis, The Chinese University of Hong Kong, Hong Kong, China.

[14] Castells, M, Ardevol, M, Qiu, J, Sey, A. (October, 2004). The Mobile Communication Society: A Cross Cultural Analysis Of Available Evidence On The Social Use Of Wireless Communication Technology. A research report prepared for the International Workshop on Wireless Communication Policies and Prospects: A Global Perspective, held at the Annenberg School for Communication, University of Southern California, Los Angeles, October 8th and 9th 2004.

[15] Chakraborty, S. 2006. Mobile Phone Use Patterns Amongst University Students: A Comparative Study Between India And USA. Unpublished Master's thesis, University of North Carolina, North Carolina, USA.

[16] Chóliz, M. 2012. Mobile-phone addiction in adolescence: The Test of Mobile Phone Dependence (TMD). Prog Health Sci, 2(1), 33-44.

[17] Chung, N. 2011. Korean Adolescent Girls Additive Use Of Mobile Phones To Maintain Interpersonal. Social Behavior and Personality. 39(10), 1349-1358.

[18] Devís-Devís, J., Peiró-Velert, C., Beltrán-Carrillo, V. J., and Tomás, J. M. 2009. Screen Media Time Use Of 12-16 Year-Old Spanish School Adolescents: Effects Of Personal And Socioeconomic Factors, Season And Type Of Day. Journal of adolescence. 32(2), 213-31. doi:10.1016/j.adolescence.2008.04.004

[19] Flanagin, A. J. 2005. IM Online: Instant Messaging Use Among College Students. Communication Research Reports. 22( 3), 175-187.

[20] Geser, H. 2006. Are Girls (Even) More Addicted? Some Gender Patterns Of Cell Phone Use. In: Sociology in Switzerland: Sociology of the Mobile phone. Online Publications. Retrieved from Zuerich, June 2006 http://socio.ch/mobile/t_geser3.pdf

[21] Glaser, M. 2007. How Mobile Phones Are Killing Face-To-Face Interactions. Retrieved from http://www.pbs.org/mediashift/2007/10/how-cell-phones-are-killing-face-to-face interactions295.html.

[22] Grellhesl, M., and Punyanunt-Carter, N. M. 2012. Using the uses and gratifications theory to understand gratifications sought through text messaging practices of male and female undergraduate students. Computers in Human Behavior. 28, 2175-2181.

[23] Griffiths, M. 1996. Behavioral Addiction: An Issue For Everybody? Employee Counseling Today. 8(3), $19-25$.

[24] Griffiths, M. 1999. Internet addiction. The Psychologist. 12, 246-250.

[25] Grunwald Associates LLC. 2013. Living and Learning with Mobile Devices: What Parents Think About Mobile Devices for Early Childhood and K-12 Learning. Retrieved from http://www.grunwald.com/reports/

[26] Hakoama, M., and Hakoyama, S. 2011. The Impact Of Cell Phone Use On Social Networking And Development Among College Student. The American Association of Behavioral and Social Sciences. 15, 1-20.

[27] Hassanzadeh, R., and Rezaei, A. 2011. Effect Of Sex, Course And Age On SMS Addiction In Students. Middle-East Journal of Scientific Research. 10(5), 619-625. 
[28] Head, M., and Ziolkowski, N. 2012. Understanding Student Attitudes Of Mobile Phone Features : Rethinking Adoption Through Conjoint, Cluster And SEM Analyses. Computers in Human Behavior. 28(6), 2331-2339. doi:10.1016/j.chb.2012.07.003

[29] Hong, F-Y., Chiu, S-I., and Huang, D-H 2012. A Model Of The Relationship Between Psychological Characteristics, Mobile Phone Addiction And Use Of Mobile Phones By Taiwanese University Female Students. Computers in Human Behavior. 28, 2152-2159.

[30] Hooper, V. and Zhou, Y. 2007. Addictive, Dependent, Compulsive? A Research Of Mobile Phone Use. A paper presented at the 20th Bled e-Conference e-Mergence: Merging and Emerging Technologies, Processes and Institutions, Bled, Slovenia.

[31] Howell, M. ,Love, S., and Turner, M. 2008. User Characteristics And Performance With Automated Mobile Phone Systems. Int. J. Mobile Communications. 6(1), 1-15.

[32] Igarashi, T., Takai, J., and Yoshida, T. 2005. Gender Differences In Social Network Development Via Mobile Phone Text Messages: A Longitudinal Study. Journal of Social and Personal Relationships. 22, 691-713.

[33] Igarashi. T., Motoyoshi. T., Takai. J. , and Yoshida. T. 2008. No Mobile, No Life: Self-Perception And Text-Message Dependency Among Japanese High School Students. Computers in Human Behavior, 24, 2311-2324.

[34] International Telecommunication Union 2013. Mobile-Cellular Subscriptions. Retrieved from http://www.itu.int/en/ITUD/Statistics/Pages/stat/default.aspx

[35] Iqbal, Z. 2010. Gender Differences in Mobile Phone Use: What Communication Motives Does it Gratify? European Journal of Scientific Research. 46(4), 510-522.

[36] Jabr, N. H. 2011. Social Networking as a Tool for Extending Academic Learning and Communication. International Journal of Business and Social Science. 2(12), 93-102.

[37] James, D. ,and Drennn, J. 2005. Exploring Addictive Consumption of Mobile Phone. A paper presented at the ANZMAC Conference: Electronic Marketing, Journal of Adolescence. 27(1), 87-96.

[38] Javid, M., Malik, M. A., and Gujjar, A. A. 2011. Mobile Phone Culture and its Psychological Impacts on Students' Learning at the University Level. Language in India www.languageinindia.com. 11( 2), 416-422.

[39] Kamran, S. 2010. Mobile Phone: Calling And Texting Patterns Of College Students In Pakistan. International Journal of Business and Management. 5(4), 26-43.

[40] Krajewska-Kułak, E., Kułak, W., Stryzhak, A., Szpakow, A., Prokopowicz, W. , and Marcinkowski J.T. 2012. Problematic Mobile Phone Using Among The Polish And Belarusian University Students: A Comparative Research. Prog Health Sci. 2(1), 45-50.

[41] Kubey, R. W., Lavin, M.J. ,and Barrows, J. R. 2001. Internet Use And Collegiate Academic Performance Decrements: Early Findings. Journal of Communication, 51, 366-382.

[42] Kwon, M., Lee, J.-Y., Won, W.-Y., Park, J.-W., Min, J.-A., Hahn, C., ... Kim, D.-J. 2013. Development and Validation of a Smartphone Addiction Scale (SAS). PloS one. 8(2), 1-7. doi:10.1371/journal.pone.0056936

[43] Lemon, J. 2002. Can We Call Behaviors Addictive? Clinical Psychologist. 6,(2), 44-49.

[44] Li, S.-M., and Chung, T.-M. 2004. Internet Function And Internet Addictive Behaviour. Computers in human behavior. $22(6), 1067-1071$.

[45] Madrid, A. 2003. Mobile Phones Becoming A Major Addiction. Retrieved from http://www.smh.com.au/articles/2003/12/10/1070732250532.html?fro m=storyrhs

[46] Matthews, T., Pierce, J.andTang, J. 2009. No Smartphone Is An Island: The Impact Of Places, Situations And Other Devices On Smart Phone Use. IBM Research Report \#RJ10452.

[47] Monk, A., Carroll, J. ,Parker, S., and Blythe, M. 2004. Why are mobile phones annoying? Behav. Info. technol. 23, 3341.

[48] Naz, A., Khan, W., Daraz, U.,and Hussain, M. 2011.The Malevolence Of Technology: An Investigation Into The Various Socio-Economic Impacts Of Excessive Cell Phone Use Among University Students (A Case Study Of University Of Malakand, KPK Pakistan). International Journal of Academic Research in Business and Social Sciences. 1(3), 321-336.

[49] Oliver, B. 2005. Australian University Students' Use Of And Attitudes Towards Mobile Learning Technologies. A paper presented at the IADIS International Conference Mobile Learning 2005. Retrieved from www.iadis.net/dl/final_uploads/200506c004.pdf

[50] Orford, 2001. Excessive Appetites: A Psychological View Of Addictions (2nd Ed.). Chichester, UK: Wiley. 
[51] Osman, M. A., Sabudin, M., Osman, A., and Shiang-yen, T. 2011. Consumer Behaviors Toward Use Of Smartphone In Malaysia, International Conference on Software Computer Applications. 9, 158-164. Retrieved from http://www.ipcsit.com/vol9/30-B033.pdf

[52] Palen, L., Salzman, M. , and Youngs, E. 2001. Discovery And Integration Of Mobile Communications In Everyday Life. Personal Ubiquitous Comp. 5, 109-122.

[53] Paragas, F., Clara, D. Y., Main, L.T., and Abdul Rahman, N. 2010. Mobile Telephony Uses And Gratifications Among Elderly Singaporeans. MEDIA ASIA. 37(4), 215-223.

[54] Pawłowska, B., and Potembska, E. 2011. Gender And Severity Of Symptoms Of Mobile Phone Addiction In Polish Gymnasium, Secondary School And University Students. Curr Probl Psychiatry. 12(4), 433-438.

[55] Perry, S., and Lee, K. 2007. Mobile Phone Text Messaging Overuse Among Developing World University Students. COMMUNICATIO. 33(2),63-79.

[56] Pierce, T.A. ,and Roberto, V. 2008. Distracted: Academic Performance Differences Between Teen Users And NonUsers Of Myspace And Other Communication Technology. Retrieved from www.iiisci.org/journal/CV\$/sci/pdfs/E214BL.pdf

[57] Pierce, T.A., and Vaca, R. 2008. Distracted: Academic Performance Differences Between Teen Users and Non-Users of MySpace and Other Communication Technology. A paper presented at the " 5 th International Conference on Education and Information Systems, Technologies and Applications. Orlando, FL.

[58] Prezza,M., Pacilli,M.G., Dinelli,S. 2004. Loneliness And New Technologies In A Group Of Roman Adolescents. Computers in Human Behavior. 20 (5),691-709.

[59] Rau, P-L. P. ,Gao, Q. , and Wu, M-L. 2008.Using Mobile Communication Technology In High School Education: Motivation, Pressure And Learning Performance. Computers and Education. 50, 1-22.

[60] Rice, R.E., and Katz, J.E. 2003. Comparing Internet And Mobile Phone Use: Digital Divides Of Use, Adoption And Dropouts. Telecommunications Policy. 27(8-9),597-623.

[61] Rodrigues, A. 2011. The Perceived Impacts Of Smartphone Use On The Performance Of Senior Managers In South African Firms. Un published Master's Thesis .University of Cape Town, South African.

[62] Ruiz-Olivares, R., Lucena, V., Pino, M.J., and Herruzo, J. 2010. Analysis Of Behavior Related To Use Of The Internet, Mobile Telephones, Compulsive Shopping And Gambling Among University Students. Adicciones. 22(4), 301-309.

[63] Satoko, F., Masahiro. T, Kimio, Y., Aki, N., Rei, D., and Kanehisa, M. 2009. Relationships Of Personality And Lifestyle With Mobile Phone Dependence Among Female Nursing Students. Social Behavior and Personality: an international journal. 37(2), 231-238.

[64] Shaffer, H. J. 1996. Understanding The Means And Objects Of Addiction: Technology, The Internet And Gambling. Journal of Gambling Studies. 12, 461-469.

[65] Shambare, R. , Rugimbana, R. ,and Zhowa, T. 2012. Are mobile phones the 21st century addiction? African Journal of Business Management. 6 (2), 573-577.

[66] Sheereen, N. Z. ,and Rozumah, B. 2009. Mobile Phone use Amongst Students in a University in Malaysia: Its Correlates and Relationship to Psychological Health. European Journal of Scientific Research, 37(2), 206-218.

[67] Srivastava, L. 2005. Mobile Phones And Evolution Of Social Behavior. Behavior and Information Technology. 24, 111-129.

[68] Sung, E., and Mayer, R. E. 2012. Students' Beliefs About Mobile Devices Vs. Desktop Computers In South Korea And The United States. Computers and Education. 59, 1328-1338.

[69] Szpakow, A., Stryzhak, A., and Prokopowicz, W. 2011. Evaluation Of Threat Of Mobile Phone - Addition Among Belarusian University Students. Prog Health Sci, 1(2), 96-101.

[70] Takao, M., Takahashi, S., and Kitamura, M. 2009. Addictive Personality And Problematic Mobile Phone Use. Cyber psychology Behavior; 12(5), 501-507.

[71] Telecommunication Regulatory Authority 2012. Quarterly Report on Telecom Market Indicators Q2, 2012 Market Research and Planning Economic Affairs Unit. Retrieved from www.tra.gov.om.

[72] Turner, M., Love, S., and Howell, M. 2008. Understanding Emotions Experienced When Using A Mobile Phone In Public: The Social Usability Of Mobile (Cellular) Telephones .Telematics and Informatics. 25(3), 201-215.

[73] Villella, C., MartinottiM, G., Di Nicola, M. , Cassano, M., La Torre, G., Gliubizzi, M. D., Messeri, I., Petruccelli, F., Bria, P., Janiri, and Conte, G. 2011. Behavioral Addictions in Adolescents and Young Adults: Results from a Prevalence Study. J Gambl Stud. 27, 203-214. 
[74] Walsh, S. P. 2009. Psychological Approach To Understanding Young Australian's Mobile Phone Behavior. Unpublished PHD dissertation. Queensland University of Technology, Australia.

[75] Walsh, S. P. ,White, K. M. and Young, R. M. 2010. Needing To Connect: The Effect Of Self And Others On Young People's Involvement With Their Mobile Phones. Australian Journal of Psychology. 62(4), 194-203.

[76] Walsh, S.P. ,White, K. M. ,and Young, R.M. 2008. Over-Connected? A Qualitative Exploration Of The Relationship Between Australian Youth And Their Mobile Phones. Journal of Adolescence. 31(1), 77-92.

[77] Walsh, S.P., White, K.M., Stephen, C., S. ,and Young, R.M. 2011. Keeping In Constant Touch: The Predictors Of Young Australians' Mobile Phone Involvement. Computers in Human Behavior. 27, 333-342.

[78] Wilska, T. A. 2003. Mobile Phone Use As Part Of Young People's Consumption Styles. Journal of Consumer Policy. 26(4), 441-463.

\section{Author' biography}

Hafidha Suleiman Al-Barashdi is a doctoral student in the Department of Information Studies at Sultan Qaboos University, Oman. She holds a Master's in Psychology. Her research interests include Smartphone addiction. She can be contacted at: p012307@squ.edu.om

Abdelmajid Bouazza is a Professor in the Department of Information Studies at Sultan Qaboos University, Oman. He received his PhD from School of Library and Information Science, University of Pittsburgh. His research interests include Internet addiction and Open access. He can be contacted at: bouazza93@gmail.com

Naeema H. Jabur is a Professor in the Department of Information Studies at Sultan Qaboos University, Oman. She received her PhD from School of Library and Information Science, University of Pittsburgh. Her research interests include Knowledge management, and information systems. She can be contacted at: mnjaburh@hotmail.com

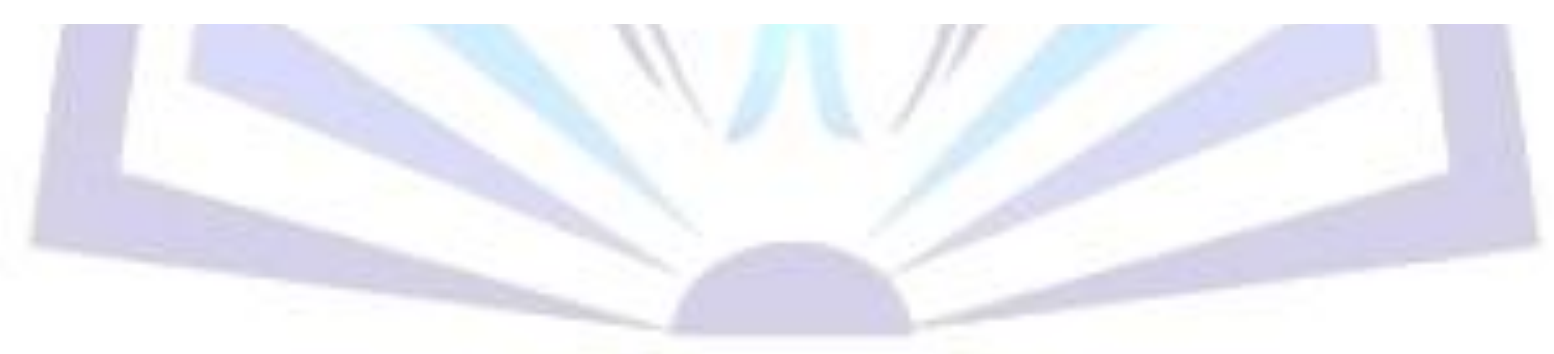


